\title{
Medium- and long-term consequences of pollution on labor supply: evidence from Indonesia
}

Younoh Kim ${ }^{1}$, James Manley ${ }^{2}$ and Vlad Radoias ${ }^{1 *}$

*Correspondence: radoias@shsu.edu

'Sam Houston State University, Huntsville, TX, USA

Full list of author information is

available at the end of the article

\begin{abstract}
We use a natural experiment in Indonesia to study the medium- and long-term effects of air pollution on labor supply. We find that exposure to air pollution reduces hours worked and while the medium-term effects are larger in magnitude, some effects do persist in the long term. More interestingly, we are able to provide some insight regarding the underlying channels that contribute to the reduced labor supply. Own health seems to be the only responsible channel in the long term, while in the medium term, a different channel based on dependent caregiving is the most important.
\end{abstract}

JEL Classification: J22, Q53

Keywords: Air pollution, Working hours, Indonesia

\section{Introduction}

A vast medical literature exists that links air pollution, especially fine particulate matter, to health ${ }^{1}$. Better air quality reduces infant mortality (Bobak and Leon 1992; Chay and Greenstone 2003a, 2003b; Currie and Neidell 2005; Loomis et al. 1999) and respiratory problems in both infants and adults (Chauhan and Johnston 2003; Emmanuel 2000; Romieu et al. 2002) and can even improve mental health and cognition (Peterson et al. 2015).

From an economic perspective, pollution has social costs that go beyond the direct costs associated with these negative health consequences. Having health problems, even transitory ones, not only imposes a direct cost on those affected but also can lead to further social losses stemming from reduced productivity or reduced labor activity of those affected. There is ample evidence in the literature that shows negative consequences of pollution on labor supply (Aragon et al. 2016; Carson et al. 2010; Hanna and Oliva 2015; Hausman et al. 1984) and on worker productivity (Chang et al. 2014; Crocker and Horst 1981; Graff-Zivin and Neidell 2012). There is also evidence that pollution affects school absenteeism, which can further affect work hours for workers taking care of these sick children (Currie et al. 2009; Gilliland et al. 2001; Park et al. 2002).

Most of the existent evidence focuses, however, only on the short-term impact of pollution. Research on its medium- and long-term effects is limited. Studying the effects of pollution over longer time horizons is important as some of its negative effects could

(c) The Author(s), 2017 Open Access This article is distributed under the terms of the Creative Commons Attribution 4.0 International License (http://creativecommons.org/licenses/by/4.0/), which permits unrestricted use, distribution, and reproduction in any medium, provided you give appropriate credit to the original author(s) and the source, provide a link to the Creative Commons license, and indicate if changes were made. 
be persistent over time and harder for exposed individuals to recover from. Among the few recent studies that try to address the issue in the long term, Kim et al. (2016) show negative effects of pollution on a range of health measures that persist even 10 years post exposure, while Isen et al. (2016) show negative effects on labor supply and earnings in the USA for those who were exposed to pollution during their early childhood.

Our paper is among the first to study the medium- and long-term effects of pollution on labor supply in a developing country and adds to the very limited evidence by studying the issue at the aggregate population level and by using a fully exogenous pollution shock, rather than achieving identification through some policy change that might be suffering from other confounders. The closest paper to our study that we are aware of is Hanna and Oliva (2015). They however differ from us in that they study the reverse phenomenon of pollution reduction. Isen et al. (2016) is another paper with a similar research question. However, they only focus on the early childhood exposure and use a policy change in the 1970s to identify the effect of pollution exposure, which is overall less persuasive than the direct evidence of pollution exposure our study uses. At the same time, an important difference between these studies and ours is that we are dealing with a relatively short but intense pollution shock, while they study a sustained decrease in pollution over time. Since the impact of pollution might not be linear, the resulting estimates need to be put in context and interpreted accordingly.

We propose to study the medium- and long-term ${ }^{2}$ effects of air pollution on labor supply, using data from Indonesia and taking advantage of a natural experiment that offers the unique opportunity of having a truly randomly assigned pollution shock. In the fall of 1997, large parts of Indonesia were engulfed in forest fires that originated with slash-and-burn practices commonly used by farmers as a cheap way of clearing land but were aggravated by the especially dry and windy season caused by El Niño. The fires burned out of control between August and November 1997, destroying over 12 million acres of land and covering much of Indonesia in smoke ${ }^{3}$. This episode has been widely used in the literature to study a variety of issues surrounding air pollution. Frankenberg et al. (2004) find older individuals exposed to the smoke are less able to perform daily activities. Jayachandran (2009) finds reduced fertility in the areas most exposed to pollution. Kunii et al. (2002) find elevated levels of respiratory illnesses during the fires, which might have indirect effects on hours worked. The pollution was so severe that even neighboring countries suffered from it. Emmanuel (2000) and Heil (2000), for instance, find an increase in respiratory illnesses and other acute health issues in Singapore, while Sastry (2002) finds increased mortality among the elderly in Malaysia. All these documented health issues could have direct effects on labor markets, and these effects could persist over time. Our paper tries to fillin this gap of the literature and study these longer-term effects of pollution on labor supply.

We find that higher pollution reduces the hours worked in both the medium- and the long term. We capture medium-term effects 3 years past exposure and long-term effects 10 years past exposure. The medium-term effects are larger in magnitude, which is consistent with a hypothesis of recovery over time, but some effects still persist 10 years after exposure. We also underline two distinct channels that lead to reduced labor supply as a result of pollution exposure: own health and dependent caregiving. 


\section{Data and Methodology}

We use data from the Indonesia Family Life Survey (IFLS). IFLS is a longitudinal survey containing a sample of households that is representative for over $80 \%$ of the Indonesian population. The first wave of the survey was fielded in 1993, with subsequent waves in $1997,2000,2007$, and $2015^{4}$. The attrition rates are very small in IFLS, and most households can be successfully tracked from one wave to another. This is ideal for our study, as we use data from the first four waves to estimate our econometric models.

Our dependent variable is hours worked per week. Respondents are surveyed on the numbers of hours they work during a typical week. We collect this information from all waves of IFLS and use the data from 2000 to 2007 as dependent variables to study the medium- and respectively long-term effects of air pollution. The data from the 1993 wave is used as a control variable proxying for the initial labor supply decision. We do not use the data from 1997 since the data collection process overlapped with the smoke months and hence the data from 1997 could already include the population response to pollution, rather than just the initial labor supply information.

The explanatory variable of interest is the pollution level that respondents were exposed to during the 1997 fires. Our measure of air pollution is the aerosol index from the Earth Probe Total Ozone Mapping Spectometer (TOMS). The aerosol index is calculated from the amount of light that polluting particles absorb or reflect and has been found to correlate closely with the particulate matter pollution measured with standard ground-based monitors (Hsu et al. 1999). The index can take values ranging from -2 to 7 , with positive numbers indicating absorbing particles such as dust and smoke and negative numbers representing non-absorbing particles such as sulfates (Jayachandran 2009). The actual observed values of the index during the fires of 1997 are solely in the positive domain and, with large magnitudes, signaling large quantities of smoke in the atmosphere. The main limitation of using this measure is that it is unit-less and does not allow meaningful quantitative analysis and comparisons with ground-based particulate measurements of pollution. The advantage is that we have data spanning large territories and long periods of time, allowing us to qualitatively analyze the long-term effects of pollution.

Following Jayachandran (2009) and Kim et al. (2016), we interpolate the TOMS data described in Jayachandran (2009) and provided to us by Dr. Jayachandran, using Global Positioning System (GPS) coordinates for each community provided by IFLS. The monthly pollution calculated as the median of the daily values in Jayachandran (2009) was averaged over the September, October, and November months of 1997 to construct the pollution variable used in all our regressions.

Table 1 contains simple summary statistics describing the pollution levels and also the labor supply decision of respondents. The unit of observation is an individual. Pollution Index 1997 represents the average pollution an individual was exposed to during the fires,

Table 1 Summary statistics

\begin{tabular}{lllll}
\hline Variable & Mean & Std. Dev. & Range & Sample size \\
\hline Pollution index 2000 & 0.253 & 0.139 & $-0.034-0.881$ & 6526 \\
Pollution index 1997 & 0.691 & 0.640 & $0.194-4.841$ & 6526 \\
Pollution index 1996 & 0.089 & 0.082 & $-0.083-0.395$ & 6526 \\
Working hours 2007 & 40.239 & 20.454 & $1-168$ & 5209 \\
Working hours 2000 & 41.858 & 21.929 & $1-168$ & 6526 \\
Working hours 1993 & 42.819 & 19.747 & $1-99$ & 6526 \\
\hline
\end{tabular}


while Pollution Index 1996 represents the average pollution during the same months of the year 1996 (to proxy for the usual background pollution, absent the fires). As mentioned above, these are unit-less indexes. Working hours represent the amount of hours each working respondent worked during a typical week. We only included working respondents in the sample to avoid complications associated with labor market participation decisions or other issues that might make respondents remain unemployed and also to avoid a particular measurement error in the IFLS ${ }^{5}$. While this might create a bias in our main estimates since some people might exit the labor force as a result of pollution, this bias would only strengthen the qualitative implications of our estimates. Unfortunately, we have to deal with the additional measurement error of people responding to have worked more than $168 \mathrm{~h}$ per week, which is physically impossible. In order to address this problem, we have decided to drop these respondents from the sample. Overall, only about $0.5 \%$ of the respondents in 2007 were dropped from the sample as being mis-measured by either having worked zero hours or having worked more than $168 \mathrm{~h}$. Note that the sample also shrinks between 2000 and 2007, due mostly to aging.

In terms of the labor supply decision, there is a small but statistically significant reduction in the average hours worked from one wave to the next. Part of this reduction is obviously due to aging, but we wish to see if some effects can be attributed to the 1997 pollution episode, which is also evident from the table. The aerosol index spiked from an average of 0.09 in 1996 to an average of 0.69 during the fires of 1997. A value higher than 0.75 represents a high level of smoke (Jayachandran 2009). Looking at the range of values, we see the index spiking as much as 4.84 and going as low as 0.194 , which ensures enough variation to identify the causal effect we wish to study. We also see the pollution dropping significantly after the fires, with pollution levels in 2000 being much lower than those observed in 1997, although not quite as low as those from 1996. We cannot say if these elevated levels are legacy impacts or simply contemporary shocks, but they do require robustness checks which are discussed later.

We argue that pollution exposure was due to a wholly exogenous phenomenon, as the spread of fires was mainly due to El Niño and not to anything else that could be correlated with individual- or household-specific socio-economic factors. We therefore treat the pollution shock as a natural experiment and simply estimate the effect of the pollution level on respondents' hours worked, 3 and respectively 10 years past exposure. We nevertheless control for initial hours worked and for other socio-economic factors that could affect hours worked. We collect extensive control data on respondents' age (in years), education level (in years of education completed), tenure at current job (in years), sex (through a male indicator variable), household size, whether they live in an urban setting, and whether their dwelling has an outdoor kitchen and water supply. Formally, the reduced form models can be written as follows:

$$
\text { Hours Worked }_{i j}^{t}=\alpha \text { Hours Worked }_{i j}^{1993}+\beta \text { Pollution }_{j}^{1997}+\gamma X_{i}+\varepsilon_{i j}
$$

where $t$ represents the year (2000 and 2007) for our two separate estimations, $i$ denotes the respondent, $j$ denotes the community, $X$ is the vector of individual and household level control variables mentioned above, and $\varepsilon_{i j}$ is the error term representing unobservables uncorrelated with the regressors. We estimate these equations with ordinary least squares (OLS) with robust standard errors. 


\section{Results}

We start with presenting the long-term results. Column 2 of Table 2 presents the results of the effects of the 1997 pollution shock on working hours in 2007. Our estimations control for age (in years) and age squared, tenure at current job (in years) and tenure squared, education (in years), a sex dummy, an urban location dummy, household size, dummies for having a kitchen and water source outside of the dwelling, and initial labor supply. For the initial labor supply, we use data on working hours in 1993, to avoid all possible contaminations with the pollution episode in 1997. All the other controls were computed for the year 2007, respectively 2000, depending on the specification. We dropped observations that were most likely mis-measured, such as those who reported working more than $168 \mathrm{~h}$ per week.

The effect of pollution on working hours, 10 years past exposure, is negative but statistically significant only at the $10 \%$ level. Although the pollution level is a unit-less index that makes interpreting the magnitude of the coefficient difficult, a standardized estimate

Table 2 Long- and medium-term regression results_full sample analysis (Dependent variable: working hours per week)

\begin{tabular}{|c|c|c|c|c|}
\hline \multirow{2}{*}{$\begin{array}{l}\text { Term (dependent variable) } \\
\text { Variables }\end{array}$} & \multicolumn{2}{|c|}{$\begin{array}{l}\text { Long-term results (Working hours } \\
\text { in 2007) }\end{array}$} & \multicolumn{2}{|c|}{$\begin{array}{l}\text { Medium-term results (Working hours in } \\
\text { 2000) }\end{array}$} \\
\hline & & & & \\
\hline \multirow[t]{2}{*}{ Pollution index in 1997} & $-0.8005^{*}$ & -0.6974 & $-1.5458^{* * *}$ & $-1.5124^{* * *}$ \\
\hline & $(0.4555)$ & $(0.4573)$ & $(0.3754)$ & $(0.3764)$ \\
\hline \multirow[t]{2}{*}{ Age (in years) } & -0.1067 & -0.1094 & -0.0062 & -0.0034 \\
\hline & $(0.2089)$ & $(0.2082)$ & $(0.1559)$ & $(0.1558)$ \\
\hline \multirow[t]{2}{*}{ Age squared } & -0.0018 & -0.0017 & -0.0023 & -0.0023 \\
\hline & $(0.0019)$ & $(0.0019)$ & $(0.0015)$ & $(0.0015)$ \\
\hline \multirow[t]{2}{*}{ Tenure (in years) } & 0.0469 & 0.0494 & -0.0204 & -0.0206 \\
\hline & $(0.0620)$ & $(0.0617)$ & $(0.0575)$ & $(0.0575)$ \\
\hline \multirow[t]{2}{*}{ Tenure squared } & -0.0014 & -0.0015 & -0.0005 & -0.0005 \\
\hline & $(0.0013)$ & $(0.0013)$ & $(0.0011)$ & $(0.0011)$ \\
\hline \multirow[t]{2}{*}{ Years of education } & $-0.2014^{* * *}$ & $-0.1976^{* * *}$ & $-0.2557^{* * *}$ & $-0.2573^{* * *}$ \\
\hline & $(0.0633)$ & $(0.0634)$ & $(0.0611)$ & $(0.0611)$ \\
\hline \multirow[t]{2}{*}{ Having outside kitchen } & -0.44 & -0.4289 & 0.2304 & 0.2179 \\
\hline & $(0.5728)$ & $(0.5726)$ & $(0.5379)$ & $(0.5381)$ \\
\hline \multirow[t]{2}{*}{ Having outside water } & $-1.6479^{* *}$ & $-1.6645^{* *}$ & $-2.0066^{* * *}$ & $-2.0169^{* * *}$ \\
\hline & $(0.7128)$ & $(0.715)$ & $(0.6458)$ & $(0.6462)$ \\
\hline \multirow[t]{2}{*}{ Living in urban location } & $5.255^{* * *}$ & $5.2541^{* * *}$ & $4.659^{* * *}$ & $4.6696^{* * *}$ \\
\hline & $(0.6202)$ & $(0.6191)$ & $(0.5919)$ & $(0.5920)$ \\
\hline \multirow[t]{2}{*}{ Male } & $3.2554^{* * *}$ & $3.1719^{* * *}$ & $2.2675^{* * *}$ & $2.2574^{* * *}$ \\
\hline & $(0.5984)$ & $(0.5983)$ & $(0.5549)$ & $(0.5558)$ \\
\hline \multirow[t]{2}{*}{ Household size } & 0.0056 & -0.0017 & 0.0217 & 0.0222 \\
\hline & $(0.1560)$ & $(0.1601)$ & $(0.1461)$ & $(0.1461)$ \\
\hline \multirow[t]{2}{*}{ Working hours in 1993} & $0.1824^{* * *}$ & $0.1827^{* * *}$ & $0.2803^{* * *}$ & $0.2807^{* * *}$ \\
\hline & $(0.0171)$ & $(0.0170)$ & $(0.0163)$ & $(0.0163)$ \\
\hline \multirow[t]{2}{*}{ Poor GHS } & - & $-1.8515^{* *}$ & - & -0.8275 \\
\hline & - & $(0.7557)$ & - & $(0.7613)$ \\
\hline \multirow[t]{2}{*}{ Constant } & $42.186^{* * *}$ & $42.3029^{* * *}$ & $36.9941^{* * *}$ & $36.9526^{* * *}$ \\
\hline & $(5.7115)$ & $(5.6931)$ & $(3.9785)$ & (3.9774) \\
\hline Sample size & 5209 & 5206 & 6526 & 6524 \\
\hline
\end{tabular}

Robust standard errors are in parentheses

*Significant at $10 \%$ level; ${ }^{* *}$ significant at $5 \%$ level; ${ }^{* * *}$ significant at $1 \%$ level 
implies that a standard deviation increase in pollution results in about $0.52 \mathrm{~h}$ decrease in labor supply. To further investigate the channel that this effect works through, we estimate a similar equation where we control for the general health of respondents. These results are presented in column 3 of Table 2. General health status (GHS) is a self-reported measure that aggregates the overall level of health. Respondents were given four choices of answers to describe their general health: unhealthy, somewhat unhealthy, somewhat healthy, and healthy. For this paper, we coded a dummy variable equal to 1 if respondents chose unhealthy or somewhat unhealthy, and 0 otherwise. GHS has been found to be a good proxy and predictor for future health (see Burstrom and Fredlund 2001, Idler and Benyamini 1997, or van Doorslaer and Gerdtham 2003). Controlling for GHS in our main specification renders the effect of pollution insignificant, which proves that own health is the main channel through which pollution negatively affects the labor supply in the long term. This fact is consistent with the findings of Kim et al. (2016) who find that air pollution affects health negatively, and these effects persist in the long term. Note that three respondents do not have information on GHS and were dropped from the regression that includes GHS. Re-estimating the first equation without including these three individuals results in virtually identical estimates.

We are also interested in studying whether the negative effects of pollution on labor supply decrease over time. We estimate a similar model where we replace the dependent variable working hours with its year 2000 level. We use the same set of control variables and again drop those observations that are likely mis-measured. The results are presented in column 4 of Table 2.

The effect of pollution on hours worked is negative, statistically significant, and larger in magnitude than the long-term effect. The standardized coefficient implies that a one standard deviation increase in pollution results in a decrease of $0.99 \mathrm{~h}$ in labor supply. This is consistent with the hypothesis that the negative effects of pollution are mitigated by the passage of time. The medium-term effects 3 years post exposure are approximately double in magnitude when compared to the long-term effects. Even more importantly, the medium-term effects do not disappear when controlling for health (column 5 of Table 2), which suggests there are additional channels other than health that can cause diminishing labor supply in the presence of air pollution. Again, two respondents do not have GHS information and were dropped from the sample, without affecting the overall results of the estimation.

One possible explanation for reduced labor supply outside of the own-health channel is caregiving. Aragon et al. (2016) find that moderate levels of pollution do not have direct effects on labor supply, but they do have indirect effects in households with children and elderly, where working adults take time off from work to care for these dependents. In order to investigate this hypothesis, we disaggregate the sample into two subsamples: households with dependents and households without dependents. We considered all children 16 or younger as dependents. The results are presented in Table 3.

We are able to confirm the care-giving channel from Aragon et al. (2016). Although their paper studies exposure to moderate levels of pollution, while ours looks at a relatively strong spike in pollution, we find care-giving to be an important channel through which pollution affects labor supply. We find that, even when controlling for health status, air pollution still has a significant negative effect on hours worked for respondents with minor dependents. For those without dependents, pollution does not seem to affect 
Table 3 Medium-term regression results—sub-sample analysis (Dependent variable: working hours per week in 2000)

\begin{tabular}{|c|c|c|c|c|}
\hline \multirow{2}{*}{$\begin{array}{l}\text { Sample } \\
\text { Variables }\end{array}$} & \multicolumn{2}{|c|}{ Households with dependents } & \multicolumn{2}{|c|}{ Households without dependents } \\
\hline & & & & \\
\hline \multirow[t]{2}{*}{ Pollution index in 1997} & $-1.719^{* * *}$ & $-1.720^{* * *}$ & -0.899 & -0.746 \\
\hline & $(0.417)$ & $(0.418)$ & $(0.865)$ & $(0.863)$ \\
\hline \multirow[t]{2}{*}{ Age (in years) } & 0.0176 & 0.1997 & -0.4006 & -0.3965 \\
\hline & $(0.1868)$ & $(0.1868)$ & $(0.3244)$ & $(0.3239)$ \\
\hline \multirow[t]{2}{*}{ Age squared } & -0.0024 & -0.0024 & 0.0005 & 0.0006 \\
\hline & $(0.0018)$ & $(0.0018)$ & $(0.0029)$ & $(0.0029)$ \\
\hline \multirow[t]{2}{*}{ Tenure (in years) } & -0.0945 & -0.0948 & 0.1527 & 0.1550 \\
\hline & $(0.0715)$ & $(0.0716)$ & $(0.1077)$ & $(0.1074)$ \\
\hline \multirow[t]{2}{*}{ Tenure squared } & 0.0007 & 0.0007 & $-0.0033^{*}$ & $-0.0033^{*}$ \\
\hline & $(0.0016)$ & $(0.0016)$ & $(0.0019)$ & $(0.0019)$ \\
\hline \multirow[t]{2}{*}{ Years of education } & $-0.263^{* * *}$ & $-0.263^{* * *}$ & $-0.266^{* *}$ & $0.266^{*}$ \\
\hline & $(0.069)$ & $(0.069)$ & $(0.135)$ & $(0.135)$ \\
\hline \multirow[t]{2}{*}{ Having outside kitchen } & -0.0182 & -0.0268 & 0.8171 & 0.7684 \\
\hline & $(0.6130)$ & $(0.6132)$ & $(1.1189)$ & $(1.1199)$ \\
\hline \multirow[t]{2}{*}{ Having outside water } & $-2.0247^{* * *}$ & $-2.044^{* * *}$ & -1.5373 & -1.4911 \\
\hline & $(0.7391)$ & $(0.7399)$ & $(1.3262)$ & $(1.3255)$ \\
\hline \multirow[t]{2}{*}{ Living in urban location } & $4.379^{* * *}$ & $4.387^{* * *}$ & $5.127^{* * *}$ & $5.151^{* * *}$ \\
\hline & $(0.677)$ & $(0.677)$ & $(1.231)$ & $(1.230)$ \\
\hline \multirow[t]{2}{*}{ Male } & $2.009^{* * *}$ & $2.017^{* * *}$ & $3.284^{* * *}$ & $3.166^{* * *}$ \\
\hline & $(0.648)$ & $(0.648)$ & $(1.097)$ & $(1.102)$ \\
\hline \multirow[t]{2}{*}{ Household size } & 0.1673 & 0.1651 & 0.3391 & 0.3426 \\
\hline & $(0.1836)$ & $(0.1837)$ & $(0.5234)$ & $(0.5223)$ \\
\hline \multirow[t]{2}{*}{ Working hours in 1993} & $0.269^{* * *}$ & $0.269^{* * *}$ & $0.311^{* * *}$ & $0.313^{* * *}$ \\
\hline & $(0.019)$ & $(0.019)$ & $(0.032)$ & $(0.032)$ \\
\hline \multirow[t]{2}{*}{ Poor GHS } & - & -0.019 & - & $-2.753^{*}$ \\
\hline & - & $(0.891)$ & - & $(1.458)$ \\
\hline \multirow[t]{2}{*}{ Constant } & $36.7447^{* * *}$ & $36.7194^{* * *}$ & $44.9515^{* * *}$ & $44.8031^{* * *}$ \\
\hline & $(4.646)$ & $(4.646)$ & (8.838) & $(8.845)$ \\
\hline Sample size & 4790 & 4788 & 1736 & 1736 \\
\hline
\end{tabular}

Robust standard errors are in parentheses

*Significant at $10 \%$ level; **significant at $5 \%$ level; *** significant at $1 \%$ level

the labor supply decision. It follows that, while there are significant negative effects of pollution on labor supply in both the medium and the long terms that are driven by respondents' own health, there are some additional effects in the medium term that are driven by dependent caregiving. The care-giving channel does not play a role in the long term arguably because, as Banerjee (2016) or Kim et al. (2016) show, in the long term, young children tend to recover from bad health episodes caused by pollution ${ }^{6}$. In the short and medium term, however, air pollution can cause serious, life-threatening health issues in young children (see for instance Gajate-Garrido 2013) and many parents are willing to take time off in order to take care of their sick children. In the absence of dependents, own health can be often disregarded by working adults who keep working normal hours, especially if the negative effects of pollution are mild in the short and medium term.

We performed a number of checks to test the robustness of this result. First, if caregiving is a channel, we would expect women to respond differently than men to pollution. We present these results in Table 4 in the Appendix. For households without dependents, 
we found the responses of pollution to be statistically insignificant for both men and women. For households with minor dependents however, we found significant coefficients for both men and women, but of largely different magnitudes. Women respond to pollution more than double in magnitude than men do. One unit of pollution reduces hours worked by $2.46 \mathrm{~h}$ for women with dependents, and by $1.17 \mathrm{~h}$ for men with dependents after controlling for own health. This strengthens the idea that care-giving is indeed the responsive channel. We also re-estimated the equations from Table 3 after re-coding the sample of households with dependents to only include those with children older than or equal to 3, who were alive during the 1997 fires and were thus directly exposed to pollution. These results are presented in Table 5 in the Appendix. We found similar results, with slightly higher magnitudes than those in Table 3, which confirms that children born after the fires were not directly exposed and therefore might not need their parents to take time off and provide caregiving. At the same time, we cannot completely rule out indirect effects through the health of the mother or in utero effects that were found to be important channels by the previous literature. In that sense, even children born after the fires might suffer due to the pollution shock and require attention.

An important remark that needs to be made is that the probability of a household having dependents is a function of pollution as well. As Jayachandran (2009) found, the number of births was significantly reduced in areas of high pollution. Since labor supply is more likely to be reduced by parents than by non-parents, these "missing children" could possibly bias our estimates. However, this bias is working in a direction that only strengthens the qualitative implications of our estimates since arguably, had these children survived, more households would have reduced their hours worked and the estimated impacts of pollution would have been larger.

\section{Robustness checks and alternative explanations}

Although the Indonesian pollution episode in 1997 was primarily driven by meteorological phenomena and such phenomena are usually considered fully exogenous and good sources of identification, we turn our attention to several issues that could potentially impact the validity of our estimates.

\subsection{Attrition}

Attrition is usually a big source of concern when dealing with longitudinal surveys like the IFLS, especially when these surveys span such a long period of time. If attrition is random, or in our case if it does not correlate with pollution, then it is not a problem. However, it is possible that respondents leave the sample systematically. If pollution affects health and the most affected respondents leave the sample, then our results will be biased. In our case, sample attrition can occur when respondents die or retire or when the IFLS loses track of them.

As mentioned in the data section, attrition rates in the IFLS are very low overall, which is encouraging for our study. Furthermore, even if we accept the possibility of a certain attrition bias, this bias would actually strengthen the qualitative implications of our estimates. If pollution were to lead to attrition, then overall we would be left with a slightly healthier sample and our estimates would be upward biased. In other words, the true impact of pollution would be actually greater (more negative) than our estimates might suggest. 
We nevertheless proceeded to investigate sample attrition between 1993 and 2007. Approximately 40\% of the respondents left the sample between 1993 and 2007. About 46\% of these respondents however were over 55 years old in 1997 and about 34\% were over 60 years old in 1997. This would suggest that most of the sample attrition comes from old retirees, rather than due to pollution.

We also ran a linear probability and a probit regression to test if the attrition status depends on the pollution exposure. We coded a dummy variable equal to 1 if the respondent was in the sample in 1993 but not in 2007 and 0 if the respondent was present in both years. We regressed this dummy variable on our main pollution variable, age and age squared, a sex dummy, and the presence of an outside kitchen and water source. The coefficient of the pollution variable was statistically insignificant, which strengthened our belief that attrition bias is not a concern for our estimates. We present these two regression in Table 6 in the Appendix.

\subsection{Economic confounders}

While the 1997 fires were undoubtedly a major pollutant in Indonesia, these fires might have had additional effects on the local economy that could have resulted in a reduction of hours worked outside of the pollution channel described in Section 3. Pollution could be for instance correlated with economic conditions in the forestry or agricultural sectors, since arguably, both these sectors were affected by the fires-agricultural land was cleared at the expense of losing the forests. These economic conditions might have affected local demand for sector-specific labor, and it is possible that our estimates pick up some of those effects as well. We tried to address some of these issues by including additional community-level controls, but this is a limitation of our study that needs to be more carefully investigated by further research.

Ideally, this issue should be addressed by considering pollution variation within local economies and very detailed data on local economic conditions, both of which we do not possess. Using community or even regional fixed effects is also not doable since the pollution episode in Indonesia occurred on such a large scale that even regional fixed effects confound with the pollution variable and render it insignificant.

The IFLS does include, however, a number of community-level variables that point to certain economic conditions that might correlate with the fires. These variables are constructed from surveying the community leaders and could suffer from mis-measurement and a dose of subjectivism. Community leaders were asked in 2007 whether their communities were still suffering from the financial crisis ${ }^{7}$, whether their communities had any wood processing or wood-related factories, whether they experienced drought and the drought frequency, and the percentage of their communities covered by forest and by farming land. We included all these variables together with a community population variable as additional controls and found very little change in our estimates. We present these results in Table 7 in the Appendix.

None of these additional controls are statistically significant, with the exception of the percentage of the community that was farm land. The inclusion of the first four controls leave the estimate of pollution virtually unchanged, while the inclusion of the farm land variable slightly decreases the point estimate of pollution from -0.87 to -1.06 . This change in the point estimate is statistically significant and consistent with the economic channel hypothesis. Since fires clear land for agriculture, higher pollution will correlate 
with more agricultural land which will lead to more hours worked in the absence of the negative effects of pollution. This bias is removed when we control for agricultural land, and the true impact of pollution seems to be more severe than initially estimated.

While the droughts, financial crisis, or the forestry sector do not seem to play roles, there are some spillovers from the fires in the agricultural sector. However, they only seem to strengthen our initial estimates. Arguably, such spillovers can occur in other sectors as well and future research should try to correct for these whenever possible. Studies using finer measures of pollution and more detailed local economic data might be more successful at addressing these concerns.

\subsection{Migration}

Temporary migration and avoidance is another possible cause of concern. If wealthier people decided to temporarily leave their communities to avoid the pollution episode, this could potentially bias our estimates. To tackle this potential problem, we looked at the respondents who migrated between September 1997 and September 1998 and tested whether their migration was determined by the pollution levels or their economic status. Just like with attrition, we coded a dummy variable equal to 1 if the person migrated during the specified period and 0 otherwise. We then regressed this dummy variable on the 1997 pollution level, the log of household per capita expenditure (PCE), age and age squared, having an outside kitchen and water source, a sex dummy, and the household size. We present these results in column 2 of Table 8 in the Appendix. We found that neither the pollution nor the economic status significantly affects the migratory status. Furthermore, only about $1.7 \%$ of respondents were found to have migrated between 1997 and 1998.

Furthermore, we employed another robustness check involving migration, similar in nature to the method described in Jayachandran (2009). We re-estimated our mediumterm regression from Table 2, column 4, but instead of matching the pollution data with the community of residence in 1997, we matched it with the community of residence in 2000. If certain people were able to avoid the pollution episode by simply migrating to another area or if the observed migration was due to the pollution episode, we should be able to estimate different coefficient using the pollution exposure at the new location of the migrants. We report these coefficients in the third column of Table 8 in the Appendix. We find virtually identical results with those from our main specification, which further confirms that migration is not a cause of concern.

\subsection{Current pollution}

Another possible confounder is the current pollution level. If certain areas of the country are more predisposed to pollution, it is possible that the past pollution from 1997 is correlated with the current pollution. Since current pollution has already been shown to affect labor supply, omitting this variable could create a bias in our estimates, and furthermore, we might wrongly attribute the effect of current pollution to the past pollution. In that respect, our results would no longer represent long-term effects of pollution, but short-term effects.

To investigate this possibility, we re-estimated our main specifications from Table 2, columns 4 and 5, and included the pollution level from 2000 as an additional regressor. We reported this in Table 9 in the Appendix. We found virtually identical coefficients for 
the 1997 pollution, while the 2000 pollution was statistically insignificant. While we were not able to replicate this robustness check for our long-term effects since we do not have pollution data in 2007, we believe the medium-term results clearly show that the current pollution and its possible correlation with the past pollution is not a cause of concern.

Most of the issues we covered, such as the financial crisis or migration, were also found to be insignificant in papers like Jayachandran (2009), although for a different outcome variable. While most of these robustness checks leave our estimates unaffected, it is important to acknowledge the possibility of additional channels that could affect hours worked and be correlated with the pollution spike in 1997. The IFLS provides the longitudinal data needed to study the long-term effects of pollution, but it does not go very deeply into recording detailed economic conditions that could serve as additional controls.

\section{Conclusions}

In this paper, we studied the medium- and long-term consequences of air pollution on labor supply. Using the Indonesian forest fires of 1997 as a natural experiment, we estimate significant negative effects of pollution on hours worked that persist over time. A back-of-the-envelope calculation involving our estimates, the average pollution levels in 1997, labor force participation rates, and minimum wages in Indonesia puts a very conservative number of about ten billion USD lost as a result of this pollution episode during the year 2000 alone. This estimate does not take into account however the large variation in both the spatial exposure to pollution and also wages. The negative consequences seem to be somewhat mitigated by the passage of time. We find the medium-term effects ( 3 years past exposure) to be approximately double in magnitude when compared to the long-term effects (10 years past exposure) and driven primarily by caregiving. The effects that persist in the long term seem to be mainly driven by respondents' own health.

A particularly interesting line of future research would be to investigate possible additional channels through which air pollution affects the labor supply in the medium and long term and also possible effects on earnings and other socio-economic indicators. Our study clearly shows that the economic costs of air pollution go well beyond the wellestablished short-term effects, with some effects persisting even 10 years past exposure. This should be extremely relevant to policy-makers, especially in developing countries where air pollution is often times a less important topic of debate and where cost-cutting industry practices are often given priority, at the expense of air quality. At the same time, parents with children are more prone to reduce their working hours during severe pollution episodes, which is also worth considering by policy-makers.

An important remark is that our paper is somewhat limited in terms of its policy implications. First, our pollution measure is a unit-less index that does not allow for meaningful quantitative calculations. Second, we are studying the effects of an extreme but relatively short-lived increase in pollution that might affect health and labor supply in a different way than the more common pollution sources that are usually more moderate in severity but last for longer periods of time. While our results might be very relevant for policies specifically targeting the slash and burn practices of farmers in developing countries, they might not be so relevant for policies targeting reducing pollution marginally in the developed world. 


\section{Endnotes}

${ }^{1}$ See Pope (2000) for a literature review on the negative consequences of pollution on health.

${ }^{2}$ While the interpretation of the terms long term and medium term can be subjective, for the purpose of this paper, we refer to a time period of 10 years as the long term and to a period of 3 years as the medium term. These periods of 10 and, respectively, 3 years are the periods between the IFLS survey rounds that are used in our empirical exercise.

${ }^{3}$ Jayachandran (2009) has a nice in-detail description of the 1997 Indonesian fires and their effects on the local economy.

${ }^{4}$ IFLS 5 was fielded in 2014-2015, with data being made available during 2016. Due to data not being fully available at the time this study was started, IFLS 5 data is not included here. It would be interesting for future research, however, to look at the new IFLS5 data as well and estimate the persistence of these effects 18 years after exposure.

${ }^{5}$ At least one survey in the IFLS coded missing responses due to respondents not answering or not being able to remember their hours worked with zeroes, rather than missing values.

${ }^{6}$ This is also consistent with other results from the economic development literature that show children can recover well from early shocks, although papers like Fedorov and Sahn (2005) or Mani (2012) that document these catch-up effects mainly focus on nutritional shocks and not pollution.

${ }^{7}$ An important financial crisis occurred in Southeast Asia during 1997-1998, and some of its effects could be correlated with the pollution episode.

\section{Appendix}

Table 4 Robustness checks—response to pollution by sex (Dependent variable: working hours per week in 2000)

\begin{tabular}{|c|c|c|c|c|}
\hline \multirow[t]{2}{*}{ Sample } & \multicolumn{2}{|c|}{ Households with dependents } & \multicolumn{2}{|c|}{ Households without dependents } \\
\hline & Men & Women & Men & Women \\
\hline \multicolumn{5}{|l|}{ Variables } \\
\hline \multirow[t]{2}{*}{ Pollution index in 1997} & $-1.1749^{* *}$ & $-2.4635^{* * *}$ & -1.9189 & 0.3728 \\
\hline & $(0.5281)$ & $(0.7080)$ & $(1.2205)$ & $(1.2713)$ \\
\hline Sample size & 3050 & 1738 & 951 & 785 \\
\hline
\end{tabular}

Robust standard errors are in parentheses. Controls included, but not reported: age, age squared, tenure, tenure squared, education, outside kitchen and water, urban location, household size, working hours in 1993, and GHS

*Significant at $10 \%$ level; ${ }^{* *}$ significant at $5 \%$ level; ${ }^{* * *}$ significant at $1 \%$ level

Table 5 Robustness checks—response to pollution by sub-sample (Dependent variable: working hours per week in 2000)

\begin{tabular}{lllll}
\hline Sample & $\begin{array}{l}\text { Households with dependents } \\
\text { (older than 3) }\end{array}$ & $\begin{array}{l}\text { Households without dependents (or } \\
\text { with dependents younger than 3) }\end{array}$ \\
\hline $\begin{array}{llll}\text { Variables } \\
\text { Pollution index in 1997 }\end{array}$ & $-1.7592^{* * *}$ & $-1.7565^{* * *}$ & -0.8946 & -0.7714 \\
& $(0.4245)$ & $(0.4261)$ & $(0.8079)$ & $(0.8046)$ \\
GHS & - & -0.0662 & - & $-2.3680^{*}$ \\
Sample size & - & $(0.9145)$ & - & $(1.3749)$ \\
\hline
\end{tabular}

Robust standard errors are in parentheses. Controls included, but not reported: age, age squared, tenure, tenure squared, education, outside kitchen and water, urban location, household size, and working hours in 1993

*Significant at $10 \%$ level; ${ }^{* *}$ significant at $5 \%$ level; ${ }^{* * *}$ significant at $1 \%$ level 
Table 6 Robustness checks —attrition (Dependent variable: attrition status indicator)

\begin{tabular}{lll}
\hline Regression model & Linear probability model (OLS) & Probit model \\
\hline Variables & & \\
Pollution index in 1997 & -0.0078 & 0.0250 \\
& $(0.0074)$ & $(0.0223)$ \\
Sample size & 8686 & 8686 \\
\hline
\end{tabular}

Robust standard errors are in parentheses. Controls included, but not reported: age, age squared, outside kitchen and water, and sex

For the probit estimation, the raw probit estimates are reported. The marginal effects are not reported, but are also statistically insignificant

${ }^{*}$ Significant at $10 \%$ level; ${ }^{* *}$ significant at $5 \%$ level; ${ }^{* * *}$ significant at $1 \%$ level

Table 7 Robustness checks—economic confounder (Dependent variable: working hours per week in 2007)

\begin{tabular}{llll}
\hline & Base model (Table 2, Col. 2) & Alt. model 1 & Alt. model 2 \\
\hline $\begin{array}{llll}\text { Variables } \\
\text { Pollution index in } 1997\end{array}$ & $-0.8005^{*}$ & $-0.8505^{*}$ & $-1.0629^{* *}$ \\
& $(0.4555)$ & $(0.5072)$ & $(0.5134)$ \\
Having wood-based industry & - & -0.6844 & -0.5296 \\
& - & $(1.1459)$ & $(1.1462)$ \\
Still affected by Fin. crisis & - & -0.8970 & -0.8264 \\
& - & $(0.5797)$ & $(0.5839)$ \\
Drought frequency & - & -0.1353 & -0.0528 \\
& - & $(0.1710)$ & $(0.1719)$ \\
Community population & - & $8.31 \mathrm{E}-08$ & $-5.43 \mathrm{E}-06$ \\
Percentage of community covered by forest & - & $(0.0000197)$ & $(0.0000188)$ \\
Percentage of community covered by farms & - & 0.0045 & -0.0184 \\
Sample size & - & $(0.0148)$ & $(0.0170)$ \\
\hline
\end{tabular}

Robust standard errors are in parentheses. Controls included, but not reported: age, age squared, tenure, tenure squared, education, outside kitchen and water, urban location, sex, household size, and working hours in 1993

*Significant at $10 \%$ level; **significant at $5 \%$ level; *** significant at $1 \%$ level

Table 8 Robustness checks-migration

\begin{tabular}{lll}
\hline Model (dependent variable) & $\begin{array}{l}\text { Determinants of migration } \\
\text { (migration indicator) }\end{array}$ & $\begin{array}{l}\text { Determinants of labor supply } \\
\text { (Hours worked in 2000) }\end{array}$ \\
\hline Variables & & $-1.5056^{* * *}$ \\
Pollution index in 1997 & 0.0017 & $(0.3862)$ \\
Sample size & $(0.0026)$ & 6244 \\
\hline
\end{tabular}

Robust standard errors are in parentheses. Controls included, but not reported for determinants of migration: age, age squared, outside kitchen and water, sex, log of PCE in 1997, and household size. Controls included, but not reported for determinants of labor supply: age, age squared, tenure, tenure squared, education, outside kitchen and water, urban location, sex, hours worked in 1993, and household size

Both models are estimated using OLS. Estimating the determinants of migration with a probit model results in similarly insignificant effects of pollution on migration

*Significant at $10 \%$ level; ** significant at $5 \%$ level; ${ }^{* * *}$ significant at $1 \%$ level 
Table 9 Robustness checks — the effects of current pollution (Dependent variable: hours worked in 2000)

\begin{tabular}{lll}
\hline Regression model & Model 1 (no GHS control) & Model 2 (with GHS control) \\
\hline Variables & & \\
Pollution index in 1997 & $-1.5205^{* * *}$ & $-1.4910^{* * *}$ \\
& $(0.3841)$ & $(0.3851)$ \\
Pollution index in 2000 & 0.5777 & 0.4912 \\
& $(1.9161)$ & $(1.9175)$ \\
Sample size & 6526 & 6524 \\
\hline
\end{tabular}

Robust standard errors are in parentheses. Controls included, but not reported: age, age squared, tenure, tenure squared, education, outside kitchen and water, urban location, sex, household size, and working hours in 1993 *Significant at 10\% level; ${ }^{* *}$ significant at $5 \%$ level; ${ }^{* * *}$ significant at $1 \%$ level

\section{Acknowledgements}

The authors would like to thank Seema Jayachandran for graciously sharing the pollution data with us. We would also like to thank the editor, Joni Hersch, and two anonymous reviewers for useful comments and remarks that improved the quality of this research.

Responsible editor: Joni Hersch

\section{Funding}

The authors declare that they have received no funding or other type of material financial benefit associated with this research.

\section{Competing interests}

The IZA Journal of Labor Economics is committed to the IZA Guiding Principles of Research Integrity. The authors declare that they have observed these principles.

\section{Publisher's Note}

Springer Nature remains neutral with regard to jurisdictional claims in published maps and institutional affiliations.

\section{Author details}

${ }^{1}$ Sam Houston State University, Huntsville, TX, USA. ${ }^{2}$ Towson University, Towson, MD, USA.

Received: 11 January 2017 Accepted: 16 March 2017

Published online: 28 April 2017

\section{References}

Aragon F, Miranda J, Oliva P (2016) Particulate matter and labor supply: evidence from Peru. Simon Fraser University Economics Working Paper

Banerjee R (2016) Long run effects of exposure to forest fires in Indonesia. working paper

Bobak M, Leon D (1992) Air pollution and infant mortality in the Czech Republic. 1986-1988. Lancet 340:1010-14

Burstrom R, Fredlund P (2001) Self rated health: is it as good a predictor of subsequent mortality among adults in lower as well as in higher social classes? J Epidemiol Community Health 55:836-840

Carson R, Koundouri P, Nauges C (2010) Arsenic mitigation in Bangladesh: a household labor market approach. Am J Agric Econ 92:1-8

Chang T, Graff-Zivin J, Gross T, Neidell M (2014) Particulate pollution and the productivity of pear packers. NBER working paper:19944

Chauhan A, Johnston S (2003) Air pollution and infection in respiratory illness. Br Med Bull 68(1):95-112

Chay K, Greenstone M (2003a) Air quality, infant mortality, and the clean air act of 1970. NBER Working Paper No:10053

Chay, K, Greenstone M (2003b) The impact of air pollution on infant mortality: evidence from geographic variation in pollution shocks induced by a recession. Q J Econ 118(3):1121-67

Crocker T. Horst R (1981) Hours of work, labor productivity, and environmental conditions: a case study. Rev Econ Stat 63:361-368

Currie J, Hanushek E, Khan M, Neidell M, Rivken S (2009) Does pollution increase school absences Review of Econ Stat 91:682-694

Currie J, Neidell M (2005) Air pollution and infant health: what can we learn from California's recent experience? Q J Econ 120(3):1003-30

Emmanuel S (2000) Impact to lung health of haze from forest fires: the Singapore experience. Respirology 5(2):175-82

Fedorov L, Sahn D (2005) Socioeconomic determinants of children's health in Russia: a longitudinal study. Econ Dev Cult Chang 53(2):479-500

Frankenberg E, McKee D, Thomas D (2004) Health consequences of forest fires in Indonesia. Demography 42(1):109-29

Gajate-Carrido G (2013) The impact of indoor air pollution on the incidence of life threatening respiratory illnesses: evidence from young children in Peru. J Dev Stud 49(4):500-515

Gilliland F, Berhane K, Rappaport E, Thomas D, Avol E, Gauderman W, London S, Margolis H, McConnell R, Islam K, Peters J (2001) The effects of ambient air pollution on school absenteeism due to respiratory illness. Epidemiology 12:43-54

Graff-Zivin J, Neidell M (2012) The impact of pollution on worker productivity. Am Econ Rev 102(7):3652-3673 
Hanna R, Oliva P (2015) The effect of pollution on labor supply: evidence from a natural experiment in Mexico City. J Public Econ 122:68-79

Hausman J, Ostro B, Wise D (1984) Air pollution and lost work. NBER working paper:1263

Heil A (2000) The 1997-98 Air pollution episode in Southeast Asia generated by vegetation fires in Indonesia. Int For Fire News 23:68-71

Hsu N, Herman J, Torres O, Holben B, Tanre D, Eck T, Smirnov A, Chatenet B, Lavenu F (1999) Comparisons of the TOMS Aerosol Index with Sunphotometer Aerosol Optical Thickness: Results and Applications. J Geophys Res 104:6269-6280

Idler E, Benyamini Y (1997) Self-rated health and mortality: a review of twenty seven community studies. J Health Soc Behav 38(1):21-37

Isen A, Rossin-Slater M, Walker W (2016) Every breath you take-every dollar you'll make: the long term consequences of the clean air act of 1970. NBER working paper:19858

Jayachandran S (2009) Air quality and early-life mortality: evidence from Indonesia's wildfires. J Hum Resour 44(4):916-954

Kim Y, Knowles S, Manley J, Radoias V (2016) Long-run health consequences of air pollution: evidence from Indonesia's forest fires of 1997. Available at SSRN: https://ssrn.com/abstract=2783402 or http://dx.doi.org/10.2139/ssrn.2783402

Kunii O, Kanagawa S, Yajima I, Hisamatsu Y, Yamamura S, Amagai T, Ismail T (2002) The 1997 haze disaster in Indonesia: its air quality and health effects. Arch Environ Health Int J 57(1):16-22

Loomis D, Castillejos M, Gold D, McDonnell W, Borja-Aburto V (1999) Air pollution and infant mortality in Mexico City. Epidemiology 10:118-23

Mani S (2012) Is there complete, partial, or no recovery from childhood malnutrition?-empirical evidence from Indonesia. Oxf Bull Econ Stat 74(5):691-715

Park H, Lee B, Ha E, Lee J, Kim H, Hong Y (2002) Association of air pollution with school absenteeism due to illness. Arch Pediatr Adolesc Med 156:1235-1239

Peterson B, Rauh V, Bansal R, Hao X, Toth Z, Nati G, Walsh K, Miller R, Arias F, Semanek D, Perera F (2015) Effects of prenatal exposure to air pollutants (polycyclic aromatic hydrocarbons) on the development of brain white matter, cognition, and behavior in later childhood. JAMA Psychiatr 72(6):531-540

Pope C (2000) Epidemiology of fine particulate air pollution and human health: biologic mechanisms and who's at risk Environ Health Perspect 108(4):713-723

Romieu I, Samet J, Smith K, Bruce N (2002) Outdoor air pollution and acute respiratory infections among children in developing countries. J Occup Environ Med 44(7):640-649

Sastry N (2002) Forest fires, air pollution, and mortality in Southeast Asia. Demography 39(1):1-23

van Doorslaer E, Gerdtham U-G (2003) Does inequality in self assessed health predict inequality in survival by income? Evidence from Swedish data. Soc Sci Med 57:1621-1629

\section{Submit your manuscript to a SpringerOpen ${ }^{\circ}$ journal and benefit from:}

- Convenient online submission

- Rigorous peer review

- Immediate publication on acceptance

- Open access: articles freely available online

- High visibility within the field

Retaining the copyright to your article

Submit your next manuscript at $\gg$ springeropen.com 